\title{
Association of a point mutation (m.9176T > G) of the MT-ATP6 gene with Leigh syndrome: A case report
}

\author{
Rozhgar A. Khailany ${ }^{1,2,}{ }^{*}$, Naser Gilani ${ }^{3}$, Mehmet Ozaslan ${ }^{3}$, Muhamad Safdar $^{4}$, Ihsan Al-Shamari ${ }^{5}$, \\ Belan O. Kanabe ${ }^{3}$, Khandakar A. S. M. Saadat ${ }^{6}$, Javad Homayounvash ${ }^{7}$, Amir Monfaredan ${ }^{8}$, \\ Mustafa S. Al-Attar ${ }^{9}$, Ahmet Arslan ${ }^{10}$
}

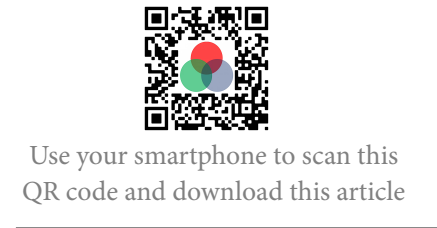

${ }^{1}$ Department of Biology, College of Science, Salahaddin University-Erbil, Iraq

${ }^{2}$ Department of Biology, Faculty of Education, Tishk International University, Erbil, Iraq

${ }^{3}$ Department of Biology, Gaziantep University, 27310 Gaziantep, Turkey

${ }^{4}$ Department of Breeding and Genetics, Cholistan University of Veterinary \& Animal Sciences, Bahawalpur, Pakistan

${ }^{5}$ Department of Internal Medicine, Hawler Medical University, Erbil, Iraq

${ }^{6}$ Department of Medical Biology, Faculty of Medicine, University of Gaziantep, Gaziantep, Turkey

${ }^{7}$ Faculty of Medicine, Tehran University of Medical Sciences, Tehran, Iran

${ }^{8}$ Department of Hematology, Faculty of Medicine, Tabriz Branch, Islamic Azad University, Tabriz, Iran

Correspondence

Rozhgar A. Khailany, Department of Biology, College of Science, Salahaddin University-Erbil, Iraq

Department of Biology, Faculty of Education, Tishk International University, Erbil, Iraq

Email: rozhgar.mohammed@su.edu.krd History

- Received: Aug 03, 2019

- Accepted: Apr 03, 2020

- Published: May 25, 2020

DOI : 10.15419/bmrat.v7i5.601

\section{Check for updates}

Copyright

( ) Biomedpress. This is an openaccess article distributed under the terms of the Creative Commons Attribution 4.0 International license.

ABSTRACT

Leigh Syndrome (LS) is an uncommon progressive neurodegenerative mitochondrial disorder. The condition is characterized by progressive mental and developmental disabilities (psychomotor regression) and commonly brings about death within a few years of diagnosis, more often due to respiratory failure. In a small number of patients the disorder does not manifest until adulthood. The principal indications of Leigh syndrome found in early stages typically are diarrhea, vomiting, and difficulty swallowing (dysphagia), which disturbs eating. These problems usually result in powerlessness to develop and put on weight under the normal rate (failure to thrive). Serious movement and muscle problems are basic in Leigh syndrome. In this case report, we introduce the molecular and clinical features of a 19-year-old female as proband, and also, we study other members of the family consequently. The m.9176T>G heteroplasmic mutation in the MT-ATP6 gene was detected by high-resolution melt (HRM) and DNA sequencing techniques. Similarly, the m.9176T>G was heteroplasmic in the mother. In conclusion, this report in compliance with previous studies underlines the necessity of further research on prenatal distinguishing proof of the responsible mutations and avoidance of the disease in families with known cases.

Key words: Mitochondrial Genome, MT-ATP6, Leigh Syndrome, Clinical Feature, Mutation

\section{INTRODUCTION}

Leigh Syndrome (LS), also known as subacute necrotizing encephalomyopathy (SNEM) is an uncommon inherited, mitochondrial DNA-associated, and severe neurodegenerative disease which is marked by bilaterally symmetrical necrotic lesions in the brainstem and basal ganglia ${ }^{1,2}$. Typically, disease onset occurs between 3 and 12 months of age and progresses to death within two years ${ }^{2}$. Prognosis is poor, but late-onset and slower progression have also been observed $^{2,3}$. LS was first described by Denis Leigh, a British neuropathologist in 1951, in a 7-month-old infant with a rapidly progressive form of the disease that resulted in death over six weeks ${ }^{4}$. LS is caused by abnormalities in mitochondrial energy generation ${ }^{5}$. Clinically, patients manifest a heterogeneous set of symptoms, including psychomotor regression (loss of mental and movement abilities), muscular hypotonia, ataxia, dystonia, respiratory insufficiency, and brainstem signs (strabismus, nystagmus and swallowing difficulties) ${ }^{1-3}$.

Genetically, LS is a highly heterogeneous mitochondrial disease ${ }^{5}$. New genetic defects are being increasingly recognized in light of novel techniques of whole- genome and next-generation sequencing ${ }^{5}$. Investigation of causative genetic defects could be a cumbersome undertaking, as researchers are confronted with two distinguished genomes- mitochondrial, and nuclear ${ }^{5,6}$. LS may be caused by defects in more than 35 different genes of either nuclear or mitochondrial origin $^{5}$. Nevertheless, the exact genetic defects, in many cases, remain unknown ${ }^{5}$.

Mitochondrially-encoded ATP synthase 6 (MTATP6) gene, also known as ATPase-6, is a key enzyme of mitochondrial energy conversion ${ }^{6}$. It is situated in mitochondrial DNA (mtDNA)- nucleotide bases 8527 to 9207 - and belongs to a family of genes termed mitochondrial respiratory chain complex ${ }^{7}$. Approximately $10-20 \%$ of individuals with LS have a mutation in mtDNA of the MT-ATP6 gene, with the most common genetic alteration being $8993 \mathrm{~T}>\mathrm{G}^{8}$. The syndromes of LS and muscle weakness, ataxia and retinitis pigmentosa (NARP), named 'striatal necrosis syndromes', are associated with mutations at nucleotide position 9176 of the MT-ATP6 gene ${ }^{8}$. The MT-ATP6 defects that lead to LS impair the stability or function of the ATP synthase complex, suppressing ATP production and damaging oxidative phosphorylation $^{8}$. 
${ }^{9}$ Department of Environmental Science, College of Science, Salahaddin

University-Erbil, Iraq

${ }^{10}$ Department of Medical Biology, Faculty of Medicine, Namik Kemal University, Tekirdag, Turkey
Here, we present the molecular and clinical features of a 19-year-old female as proband affected by LS associated with the mtDNA defect, and we also consequently evaluate other members of the family.

\section{CASE PRESENTATION}

The proband is a 19 years old female patient born to consanguineous Arab parents after a regular pregnancy and delivery, referred to genetic laboratory by a Neurologist. Her parents are first cousins (Figure 1); they are an Arab family from the Anbar Province of Iraq living in Erbil as war refugees. Phenotypically, the parents are normal, with no signs and symptoms of LS. Upon evaluation, the proband had retinitis pigmentosa, progressive dementia, and muscle weakness. Her problems started when she was in her early twenties, with movement disabilities and muscle weakness, followed by hearing and vision problems; after that, she could not speak normally. There was also a history of seizures.

On ultrasound of ophthalmic cavities, there were a few thin bands in the left vitreous cavity, and the posterior wall of both globes was thick with the irregular inner surface. The electroencephalography (EEG) examination showed short runs and frequent bursts of bilateral synchronous spikes, polyspikes, sharp waves, slow-wave complexes, and phase reversal. Magnetic resonance imaging (MRI) showed slightly dilated cerebrospinal fluid (CSF) spaces, suggestive of diffuse brain atrophic changes (Figure 2). Unfortunately, before we finished her evaluations, she died due to respiratory failure.

On molecular investigations, we studied four different known mutations as follows: $3243 \mathrm{~A}>\mathrm{G}$ in the $M T$ TL1 gene, $8344 \mathrm{~A}>\mathrm{G}$ in the $M T-T K$ gene, as well as $\mathrm{m} .9191 \mathrm{~T}>\mathrm{C}$ and $\mathrm{m} .9176 \mathrm{~T}>\mathrm{G}$ in the MT-ATP6 gene. The mutations were assessed by monitoring highresolution melt (HRM) and nucleotide sequencing techniques. The case had $\mathrm{m} .9176 \mathrm{~T}>\mathrm{G}$ mutation in the MT-ATP6 gene (Figures 3 and 4), resulting in an amino acid substitution of Leu to Arg of ATPase-6. However, there were no mutations in the other three locations.

The family has a history of early childhood death of their four offspring (three girls and one boy); three of them passed away in their first year of life and one passed away in her 4 th year. All of them died due to respiratory failure. The parents had five live offspring, including four girls (the proband passed away in the course of our investigations), and one boy (three of them have abnormal phenotypes). After the detection of a mutation in MT-ATP6 in the proband, we decided to study all family members by molecular anal- yses. The clinical characteristics and molecular investigations of the living children and their mother are shown in Table 1. Notably, the mtDNA investigations of the mother at that position demonstrated that she was heteroplasmic for the mutation.

\section{DISCUSSION}

Leigh syndrome is an uncommon inherited, neurometabolic, subacute necrotizing encephalopathy that affects the central nervous system, and occurs in 1 of 40,000 newborns worldwide and 1 of 2,000 newborns in certain populations of Saguenay LacSaint-Jean region of Quebec, Canada ${ }^{3}$. Leigh syndrome is a serious, multisystem and progressive metabolic neurodegenerative disorder, with distinct neuroradiological and neuropathological alterations as well as prominent clinical and genetic heterogeneity $^{5}$.

With current genetic diagnostic technology, Leigh syndrome has been diagnosed to be the result of mutations in more than 35 distinct genes of either nuclear or mitochondrial origin, including in each of the five respiratory chain complexes ${ }^{5}$.

In the study herein, we detected a point substitution mutation of the MT-ATP6 gene (m.9176T $>\mathrm{G})$ in a patient from Iraq. Similarly, Motohiro et al. (2012) reported the same mutation of ATP6 in Leigh syndrome ${ }^{9}$.

The clinicopathological features of the mutated case include retinitis pigmentosa, progressive dementia, and muscle weakness. MT-ATP6 is one of the mitochondrial genes that is involved in ATP production through the oxidative phosphorylation process and mutation $(\mathrm{m} .9176 \mathrm{~T}>\mathrm{G})$ of this gene results in a defect at complex V, and subsequently harms the capacity of the proton channel, resulting in loss of ATPsynthetic activity ${ }^{10}$. Alteration of this gene gives rises to the most well-known maternally-inherited Leigh syndrome (MILS), as the most widespread mtDNA mutation in Leigh syndrome ${ }^{5}$.

The ATP synthase enzyme is a multi-subunit complex with a molecular mass of around 550,000 $\mathrm{Da}^{5}$. It has both a hydrophilic ATPase and a hydrophobic domain $^{5}$. ATP synthase deformities might be of either nuclear or mitochondrial genetic origin since the biogenesis of the mitochondrial ATP synthase has 14 subunits that are nuclear-encoded, in addition to 2 mtDNA-encoded proteins ${ }^{5}$.

Regarding the mutation, Carrozzo et al. has found inactive ATP synthetase in E. coli ${ }^{9}$. From this evidence, the mutation is believed to be a neurotic and vital part of the amino acid leucine at that position in ATPase ${ }^{11}$. Along with a mtDNA mutation at nucleotide 8993 , 


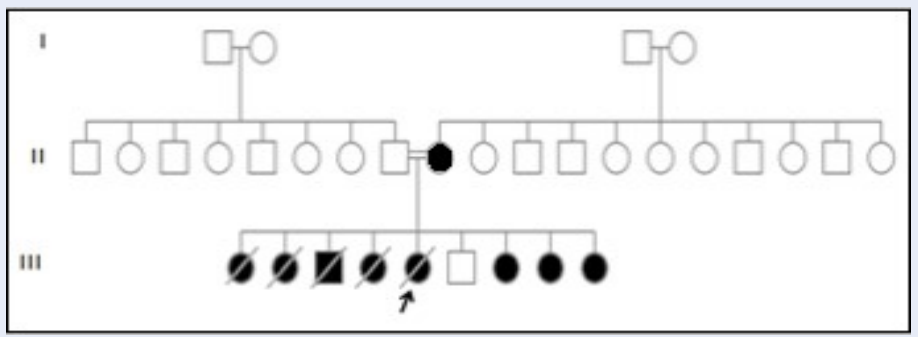

Figure 1: Family pedigree of the case. The proband is a female patient born to consanguineous parents. The family has a history of early childhood death for their 4 offsprings. Parents had 5 live offsprings, 4 girls and a boy ( 3 of them have abnormal phenotypes).

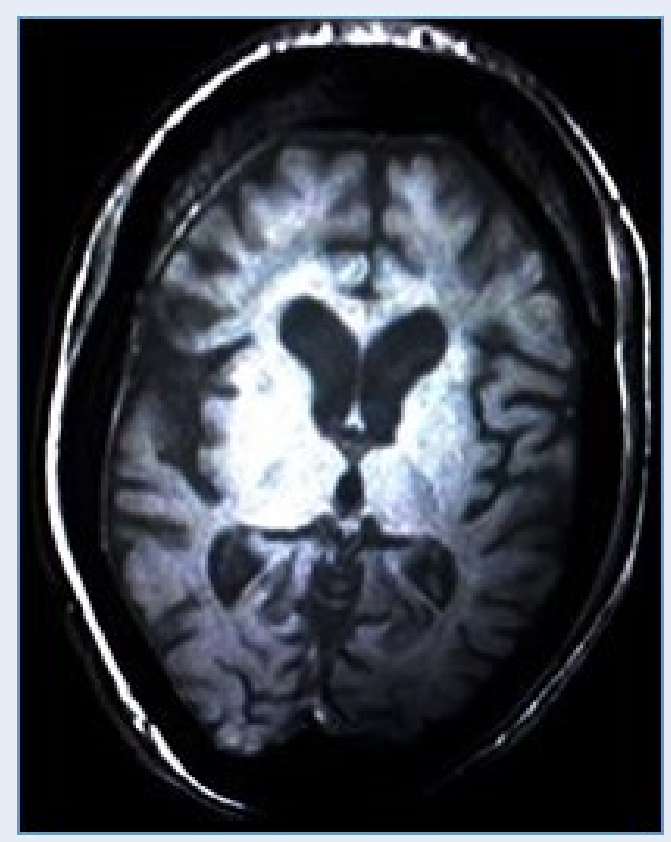

Figure 2: Brain MRI picture. It showed slightly dilated CSF spaces suggestive of diffuse brain atrophic changes.

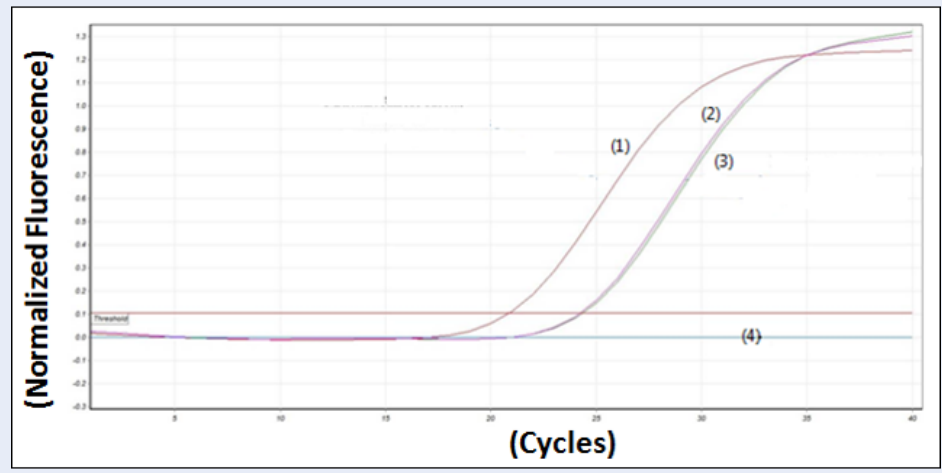

Figure 3: Normalized graph of high-resolution melting analysis conation normal and mutant alleles. (1) Mutant allele inpatient, (2) Normal allele inpatient, (3) Mutant allele in normal and (4) Normal allele in normal. 


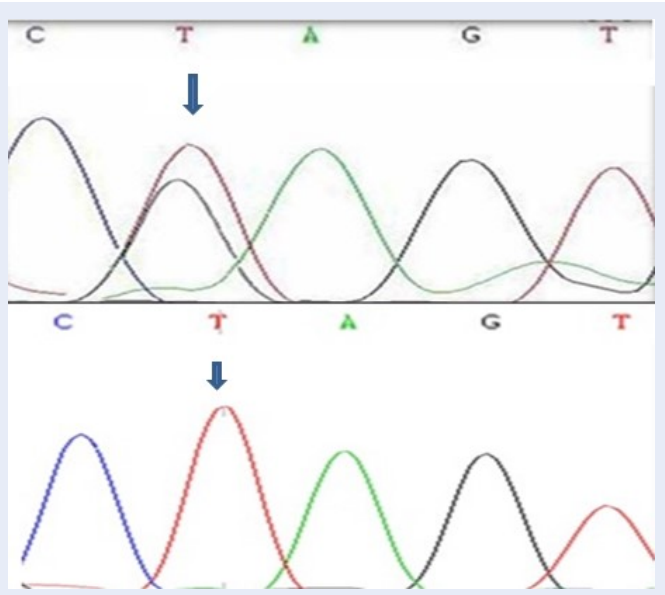

Figure 4: DNA sequencing results. It showing the m.9176T > G heteroplasmic mutation in the MT-ATP6 gene in LS patients.

Table 1: The clinical characteristics and molecular investigation of the family

\begin{tabular}{lll}
\hline Family Member & Clinical Findings & Molecular Investigation \\
\hline Mother & Asymptomatic & MT-ATP6 (m.9176T $>\mathrm{G})$ detected \\
20 months old girl & $\begin{array}{l}\text { General muscular weakness, hearing loss, hypo- } \\
\text { tonia, dysphasia, limited movements }\end{array}$ & MT-ATP6 (m.9176T $>\mathrm{G})$ detected \\
& $\begin{array}{l}\text { Vision problem in darkness from her 3 years of } \\
\text { age, there is no other sign and symptom }\end{array}$ & MT-ATP6 (m.9176T $>\mathrm{G})$ detected \\
& $\begin{array}{l}\text { Her vision problem started when she was 9 years } \\
\text { old and finally lead to complete blindness in 11 }\end{array}$ & MT-ATP6 (m.9176T $>\mathrm{G})$ detected \\
& $\begin{array}{l}\text { years of age, normal mental function, normal } \\
\text { neuromuscular examination }\end{array}$ & \\
& $\begin{array}{l}\text { No history of any kind of mental and movement } \\
\text { disability, normal neuromuscular exam, plays } \\
\text { football sometimes }\end{array}$ & MT-ATP6 (m.9176T $>\mathrm{G})$ not detected \\
\hline
\end{tabular}

having a T-to-G or T-to-C mutation provides solid proof to the significance of ATP synthetase brokenness in maternally-inherited Leigh syndrome ${ }^{9,10}$.

\section{CONCLUSION}

Leigh syndrome is a genetically heterogeneous disorder characterized by a vast spectrum of phenotypes and a variable disease course. This report corroborates previous studies since our findings in this case report comply with other case reports of this rare syndrome. Particularly, in this crowded family with nine kids, we observed considerable clinical variability among the siblings since 5 of them had passed away, while the 3 living sibling show a different clinical picture. Finally, there is a clinically normal 18 year-old male offspring. Our case report may provide a rationale for examinations utilizing cells or tissues from these patients in order to identify novel genes and novel mechanisms involved in the maintenance and assembly of the mitochondrial complex in this syndrome.

\section{ABBREVIATIONS}

MT-ATP6: Mitochondrially encoded ATP synthase membrane subunit 6

LS: Leigh Syndrome

HRM: High-resolution melting

SNEM: Subacute necrotizing encephalomyopathy mtDNA: Mitochondrial DNA

NARP: Neuropathy, ataxia, and retinitis pigmentosa ATP: Adenosine triphosphate

EEG: Electroencephalography

MRI: Magnetic resonance imaging

CSF: Cerebrospinal fluid 
MT-TL1: Mitochondrially encoded tRNA leucine 1 MILS: Maternally inherited Leigh syndrome

\section{ACKNOWLEDGMENTS}

Not applicable.

\section{AUTHOR'S CONTRIBUTIONS}

Rozhgar A. Khailany and Naser Gilani: Conceived and designed the experiments, Rozhgar A. Khailany, Naser Gilani, Mehmet Ozaslan, Muhamad Safdar: preparation and article reviewing, Rozhgar A. Khailany, Naser Gilani and Amir Monfaredan: performed the experiments, Ihsan Al-Shamari: Clinical presentation, Mehmet Ozaslan, Muhamad Safdar, Belan O. Kanabe, Khandakar A. S. M. Saadat, Javad Homayounvash, Mustafa S. Al-Attar and Ahmet ARSLAN: Interpretation and drafting article and revising it critically. All authors read and approved the manuscript.

\section{FUNDING}

Not applicable.

\section{AVAILABILITY OF DATA AND MATERIALS}

Data and materials used and/or analysed during the current study are available from the corresponding author on reasionable request.

\section{ETHICS APPROVAL AND CONSENT TO PARTICIPATE}

This study was conducted in accordance with the amended Declaration of Helsinki. The institutional review board approved the study (approval number: 3/1/1011-2016), and all participants provided written informed consent.

\section{CONSENT FOR PUBLICATION}

The author hereby consents that the publisher publishes the work.

\section{COMPETING INTERESTS}

The authors declare that they have no competing interests.

\section{REFERENCES}

1. Shrikhande DY, Kotalaki P, Syed MMA, Ahya K, Singh G. A rare mitochondrial disorder: Leigh syndrome - a case report. Italian Journal of Pediatrics. 2010;36:62. PMID: 20843336. Available from: https://doi.org/10.1186/1824-7288-36-62.

2. Ronchi D, Cosi A, Tonduti D, Orcesi S, Bordoni A, Fortunato $F$, et al. Clinical and molecular features of an infant patient affected by Leigh Disease associated to m.14459G > A mitochondrial DNA mutation: a case report. BMC Neurology. 2011;11:85. PMID: 21749722. Available from: https://doi.org/ 10.1186/1471-2377-11-85.

3. Dinesh P, Raj MM, Gita S. Leigh Syndrome: An Unusual Rare Case Report. Int J Sci Stud. 2014;2(2):93-96.

4. Horva'th R, Abicht A, Holinski-Feder E, Laner A, Gempel K, Prokisch $\mathrm{H}$, et al. Leigh syndrome caused by mutations in the flavoprotein (Fp) subunit of succinate dehydrogenase (SDHA). J Neurol Neurosurg Psychiatry. 2006;77:74-76. PMID: 16361598. Available from: https://doi.org/10.1136/jnnp.2005. 067041.

5. Akagi M, Inui K, Tsukamoto H, Sakai N, Muramatsu T, Yamada $M$, et al. A point mutation of mitochondrial ATPase 6 gene in Leigh syndrome. Neuromuscul Disord. 2002;12:53-55. Available from: https://doi.org/10.1016/S0960-8966(01)00242-5.

6. Houštěk J, Pícková A, Vojtíšková $A$, Mráček T, Pecina P, Ješina P. Mitochondrial diseases and genetic defects of ATP synthase. Biochimica et Biophysica Acta. 2006;1757:1400-1405. PMID: 16730639. Available from: https://doi.org/10.1016/j.bbabio. 2006.04.006.

7. ;Available from: https://www.ncbi.nlm.nih.gov/gene? $\mathrm{Db}=$ gene\&Cmd=DetailsSearch \&Term $=4508$.

8. pez Gallardo1 EL, Emperador1 S, Solano1 A, Llobet1 L, Martı'nNavarro1 A, pez Pe'rez1 MJL, et al. Expanding the clinical phenotypes of MT-ATP6 mutations. Human Molecular Genetics. 2014;23(23):6191-6200. PMID: 2498921. Available from: https://doi.org/10.1093/hmg/ddu339.

9. Akagia M, Inuia K, Tsukamotoa $H$, Sakaia N, Muramatsua $T$, Yamadaa $M$, et al. A point mutation of mitochondrial ATPase 6 gene in Leigh syndrome. Neuromuscular Disorders. 2002;12:53-55. Available from: https://doi.org/10.1016/S09608966(01)00242-5.

10. Tatuch $\mathrm{Y}$, Robinson BH. The mitochondrial DNA mutation at 8993 associated with NARP slows the rate of ATP synthesis in isolated lymphoblast mitochondria. Biochem Biophys Res Commun. 1993;192(1):124-128. PMID: 8476414. Available from: https://doi.org/10.1006/bbrc.1993.1390.

11. Dahl HHM. Getting to the nucleus of mitochondrial disorders: identification of respiratory chain-enzyme genes causing Leigh syndrome. Am J Hum Genet. 1998;63:15941597. PMID: 9837811 . Available from: https://doi.org/10.1086/ 302169. 